\title{
Analysis
}

\section{The efficacy of PPE for COVID-19-type respiratory illnesses in primary and community care staff}

\section{BACKGROUND}

The coronavirus disease 2019 (COVID-19), caused by the severe acute respiratory syndrome coronavirus 2 (SARS-CoV-2), is now a pandemic with devastating implications for populations, healthcare systems, and economies globally. Many healthcare workers (HCWs), including those in primary and community care settings, may be at increased risk of COVID-19 infection. ${ }^{1}$ COVID-19 is known to have three modes of transmission: contact (direct or via a fomite, that is, a contaminated surface or object), droplets Ifrom the respiratory tract of an infected individual during coughing or sneezing transmitted onto a mucosal surface or conjunctiva of a susceptible individual), and aerosols Imicrobes within droplets that remain suspended in air for long periods). ${ }^{2,3}$ Personal protective equipment (PPE) reduces the transference of droplets or other body fluids onto HCWs' skin and clothing or directly onto the mucous membranes of the eye or nasopharynx. PPE can also include respiratory protective equipment to protect against aerosol inhalation. Concerns have, however, been raised about PPE provision for preventing COVID-19 in primary and community care staff. ${ }^{4}$ This is a particularly pressing concern given the anxiety and stress of working in conditions that may pose a threat to health and which can negatively impact the productivity and care provided by HCWs. ${ }^{5}$ In this article we present findings from rapid reviews conducted regarding PPE for frontline primary care and community care staff, and what circumstances may potentially put HCWs at risk of contagion.

\section{CURRENT GUIDANCE}

Most guidance on PPE appears skewed to secondary care settings lemergency department or inpatient) and focuses mainly on 'high-risk' scenarios, for which full aerosol, droplet, and contact PPE (that is, disposable gloves, gown, eye protection, and respirator masks) are recommended. The highest number of contacts in many healthcare settings, however, will be within primary and community environments, including not just general practices but also pharmacies (where patients with symptoms may attend) and care homes. Although it is often assumed that primary and community care settings may be at 'low risk' compared

"Concerns have ... been raised about PPE provision for preventing COVID-19 in primary and community care staff.

with secondary care, in reality the varied caseload of primary care will include some higher-risk activities, such as in residential care homes where there may be close prolonged contact, and exposure of the HCW to fomites, droplets, and aerosols (for example, from chest physiotherapy).

Public Health England has produced guidance on when to use the different kinds of masks ${ }^{4}$ and how and when to use PPE laerosol-generating procedures [AGP]). ${ }^{6}$ These documents emphasise the need to: 1) assess the level of risk of infection, especially whether an AGP will be involved, before deciding which protective equipment to wear; 2l perform hand hygiene, remove jewellery, tie hair back, and hydrate (feedback from frontline: also go to the lavatoryl before donning equipment; and 3) don and doff equipment in a way that minimises self-contamination.

The World Health Organization (WHO) distinguishes different levels of risk, which include: 1) triage (implicitly, by non-clinical staff without prolonged contact: requires hand hygiene and mask); 2) suspected or confirmed case of COVID-19 requiring healthcare facility admission and no AGPs (requires hand hygiene, mask, gown, eye protection, gloves); and 3) suspected or confirmed case of COVID-19 requiring healthcare facility admission and AGP or collection of specimens for laboratory diagnosis (requires hand hygiene, respirator, gown, eye protection, gloves). The WHO guidance, ${ }^{7}$ which can be seen as a minimum standard, is intended for all healthcare settings but appears to be mainly targeted at specialist care lemergency department or inpatient) settings. A more recent WHO statement has provided advice on the use of masks in the community, during home care, and in healthcare settings with reported COVID-19 cases. It also provides guidance for decision makers on the use of masks for healthy individuals in the community setting. ${ }^{8}$ A key recommendation is that individuals working in clinical areas (that is, community health workers and caregivers) should continuously wear a

Figure 1. Controlling exposures to occupational hazards: a suggested hierarchy of controls methods. Source: Centers for Disease Control and Prevention, National Institute for Occupational Safety and Health ${ }^{10}$

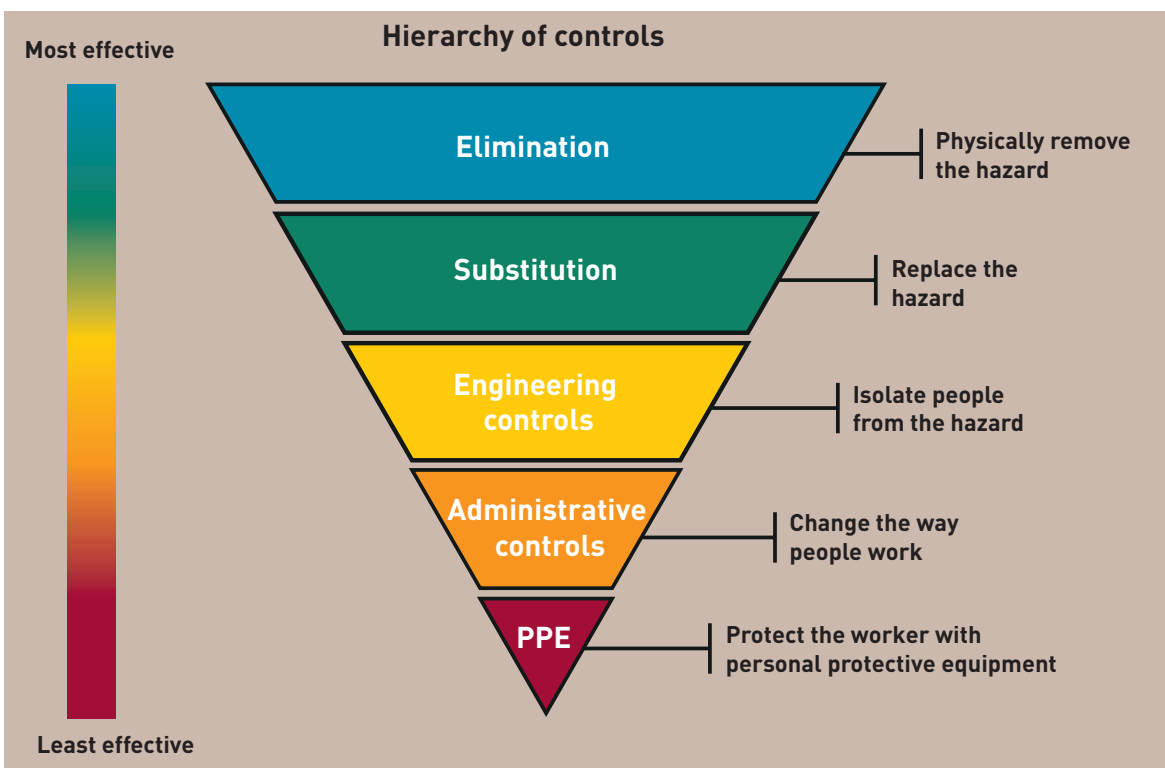




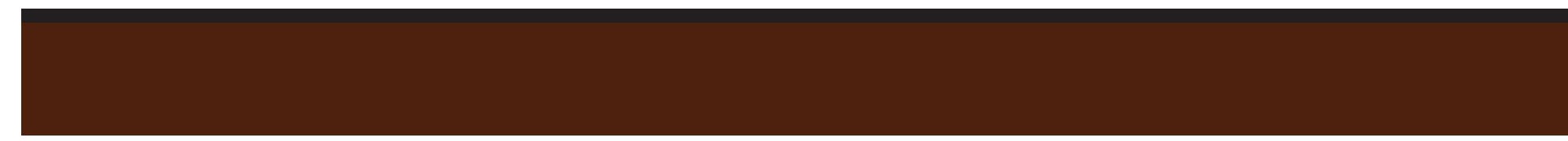

"We identified indirect evidence, mainly from singlecentre experimental studies, which support ... the correct and appropriate use of PPE according to WHO and PHE guidelines by those working in primary and community care to protect against COVID-19."

medical mask during their routine activities. Particulate respirators (for example, N95) are recommended in any settings where AGPs are performed for COVID-19 patients.

In the context of national and international guidelines strongly recommending PPE in primary and community care settings, a concept that has perhaps received insufficient attention, but which should be noted, is that of a hierarchy of exposure controls for protecting healthcare workers. In this hierarchy of controls, the most preferred and effective measure is the elimination of the hazard and the least preferred and effective measure is PPE (Figure 1). ${ }^{9}$ Therefore, PPE is only one element of a comprehensive risk reduction approach for health and care workers. Additional means of reducing exposure and disease risk, based on a risk assessment for health and care staff, could include engineering controls such as enhanced ventilation, administrative controls by re-organising work to minimise direct patient contact through remote working, and cleaning of work surfaces and hand-hygiene promotion.

\section{SEARCH STRATEGY}

We conducted four separate systematic searches of MEDLINE and Cochrane databases without date restrictions to identify anyadditional relevant randomised trialsand/ or systematic reviews evaluating the efficacy of: 1) face masks; 2) gowns/aprons; 3) eye protection; or 4) shoe covers for preventing COVID-19 in primary and community care staff. We also employed snowball searching using Twitter and Google Scholar lidentifying key references and following their citations). We used search terms combined as follows: Set 1: ICOVID OR ([TW] coronavirus OR sars OR mers OR respiratory infection) OR ([MESH] Coronavirus OR SARS Virus OR Severe Acute Respiratory Syndrome OR Middle East Respiratory Syndrome Coronavirus OR Respiratory Tract Infections OR Infections OR exp Influenza)); combined with Set 2: ("randomized controlled trial" OR "systematic review"); combined with four respective sets of terms for 1 ) masks ([TW] masks); 2) gowns/aprons ([TW] gown OR apron OR smock OR protective clothing); 3) eye protection ([TW] goggle/s OR visor OR "facial protection equipment" OR "safety glass/es" OR "safety spectacles") OR ([MESH] "Eye Protective Devices"); and 4) shoe covers "([MESH] Shoes) or ([TW] shoe/s OR overshoe OR rubber boot/s). Searches were conducted as part of a rapid evidence service for the Centre for EvidenceBased Medicine, University of Oxford. ${ }^{10-13}$ All included studies were summarised using a narrative synthesis approach.

\section{Face masks}

The standard surgical mask is designed to provide a barrier to splashes and droplets impacting on the wearer's nose, mouth, and respiratory tract. It fits fairly loosely to the user's face. These single-use masks are suitable for a variety of procedures in community and hospital settings. The respirator mask available in North America as an N95 mask, and in the UK as an FFP2/ FFP3 ('filtering face piece') mask, protects against inhalation of small airborne particles in AGPs. ${ }^{14}$

We identified a recent meta-analysis done by the Chinese Cochrane Centre, published in early March 2020 via snowball searching (this was the only source review identified for face masks). ${ }^{15}$ No additional relevant trials or reviews were identified via database searching. The meta-analysis evaluated standard surgical masks versus respirator (N95) masks and included six randomised controlled trials (RCTs) with a total of 9171 participants with influenza-like illnesses Ithat is, pandemic strains [including coronavirus], seasonal influenza A or B viruses, and zoonotic viruses such as avian or swine influenza). There were no statistically significant differences in the efficacy of standard surgical masks and respirators in preventing laboratory-confirmed influenza, laboratory-confirmed respiratory viral infections, laboratory-confirmed respiratory infections, and influenza-like illness, but respirators protected better against bacterial colonisation. This provides cautious support for the use of standard surgical masks in non-AGPs, though the empirical studies supporting this conclusion were not in a COVID-19 population.

In a recent study, SARS-CoV-2 survived airborne as long as SARS-CoV (the virus that causes SARS) when artificially aerosolised and persisted longer on some surfaces. ${ }^{16}$ This latter finding is relevant because it suggests that deposited particles may become re-suspended, that is, airborne, when disturbed.

\section{Gowns and aprons}

We found no relevant trials comparing the effectiveness of gowns against aprons. Exposure simulation studies suggest that the risk of exposure in $\mathrm{HCWs}$ is greater with aprons than with gowns but do not provide sufficient data to quantify those risks in the context of primary or community care. The WHO minimum guidance recommends long-sleeved non-sterile gowns for both AGPs and non-AGPs. ${ }^{7}$

Jefferson et al ${ }^{17}$ included four case control studies investigating SARS and extent of gown wearing, all of which were conducted in hospitals. Univariate analysis indicated protection against infection from gown wearing (compared with not wearing), but in multivariate analysis the effect of gowns was not statistically significant. Gowns were generally worn as part of the ensemble of PPE.

Verbeek et al ${ }^{18}$ included 12 studies that simulated exposure either to droplets or splashed liquids. Of these, two studies, Guo et $a l^{19}$ and Hall et al, ${ }^{20}$ compared contamination relating to wearing and doffing of gown versus plastic apron. Both used a spray to simulate droplet spread. Guo et all compared disposable waterproof gown versus apron, and Hall et al20 compared 'basic level' personal PPE - including mask, gloves, and apron - against various combinations of 'suspected case' PPE lall of which included respirator mask, gown or coverall, head covering, double gloves, and boots) in a simulated exposure setting comparable with conducting AGPs. Guo et al ${ }^{19}$ found that wearing an apron led to more direct contamination from the spray and more indirect contamination and spillage during doffing compared with disposable waterproof gown. Hall et a $l^{20}$ concluded that the basic-level PPE did not provide adequate protection for assessment of a suspected high-consequence infectious disease. It appears that the aprons in these studies were both considerably thicker than those typically provided for frontline NHS staff - Guo et all $l^{9}$ used non-woven aprons of 290 micron thickness and the UK specification for level one aprons is 16 microns. ${ }^{21}$ 
“...PPE is only one component of infection prevention, and control measures should also include appropriate engineering and administrative controls such as adequate ventilation and visitor controls.

Several studies have emphasised that, although protective clothing and other measures provide protection during wear, donning and doffing of PPE involves complex manoeuvres that are often unfamiliar to staff. Guideline violations and contamination will therefore be common, particularly during doffing. Practical training, rehearsal, and buddying all appear to improve protocol adherence. Although aprons are believed to shed droplets to the floor, we did not find studies examining secondary shedding of droplets from plastic aprons when removing them in unfamiliar spaces or even outdoors.

\section{Eye protection}

There is no evidence from RCTs that eye protection alone prevents transmission of COVID-19. Most real-world research evaluating the effectiveness of eye protection for biological hazards has been in the context of influenza or other relatively benign respiratory conditions and based in hospitals. Current guidance is therefore based on indirect evidence notably, simulations using data from SARS and MERS outbreaks - as well as expert opinion, custom, and practice.

A systematic review ${ }^{22}$ of 40 studies of the risk of nosocomial respiratory syncytial virus (RSV) infection included four studies on the effect of PPE; the authors suggested that eye protection was more effective than gowns and masks. In the systematic review, two studies in which staff eye protection was used leye-nose goggle or goggles plus masks) found this to be effective in preventing transmission of infection to staff. The conclusion is largely based on the single study of an 'eye nose goggle' la short face shield) without respiratory protection, ${ }^{23}$ compared with no facial or respiratory protection. However, most studies made some use of PPE lwhich included gowns, gloves, surgical or respirator masks, or goggles) and were conducted in neonatal and paediatric settings.

\section{Shoe covers}

Current guidance on PPE in the context of COVID-19 does not specifically mention shoe covers. We found no relevant trials. In a single observational study, a single positive swab for SARS-CoV-2 was obtained from the shoe of a healthcare worker. ${ }^{24}$ General occupational health guidance recommends shoe covers when there is a risk of splashing from infected body fluids. Further research is needed on whether shoe covers should be added to COVID-19 PPE.

One recent observational study in a dedicated COVID-19 outbreak centre in Singapore collected PPE swabs from study physicians on their exiting airborne isolation rooms of COVID-19 patients. Out of the three staff members assessed, one PPE swab, from the surface of a shoe front, was positive, and concomitant widespread environmental high-touch surface contamination was confirmed. ${ }^{24}$ Further study at this healthcare facility was expanded to 30 healthcare staff caring for infected patients, and PPE contamination was not identified. However, none of the infected patients were receiving ventilatory support and AGPs were not carried out during sampling. In addition, patients were all in airborne infection isolation rooms undergoing a minimum of 12 air exchanges/ hour and the median time that healthcare staff spent in these rooms was 6 minutes. ${ }^{25}$

There is little real-world research comparing different combinations of PPE in the context of influenza or other relatively benign respiratory conditions in primary and community care, and there are no head-tohead trials of these interventions related to SARS-CoV-2 in any setting. This is a potential limitation, as the applicability of findings from studies on other viral infections to the current SARS-CoV-2 setting is not known. Our review found little direct evidence of the efficacy of PPE in primary or community care. We identified indirect evidence, mainly from single-centre experimental studies, which may have uncertain generalisability to the real-world setting. Nonetheless, they support the correct and appropriate use of PPE according to WHO and PHE guidelines by those working in primary and community care to protect against COVID-19.

In the use of PPE, it is important to highlight

\section{CONCLUSION}

that all protective equipment should not be considered as isolated interventions. The COVID-19 PPE ensemble includes masks, gowns, eye protection lgoggles or face shields), and gloves. ${ }^{6,8}$ In relation to the minimal type of protective equipment that should be used, the WHO has produced technical specifications for these items, based on simulation exercises using data from past SARS and MERS outbreaks. ${ }^{26}$ In addition, it should be noted that effective training, ongoing evaluation, and appropriate support for the increased workload ${ }^{27}$ are also essential parts of any PPE programme because the correct donning, doffing, and disposal are key to HCW protection. Finally, PPE is only one component of infection prevention, and control measures should also include appropriate engineering and administrative controls such as adequate ventilation and visitor controls.

\section{Kamlesh Khunti,}

Professor of Primary Care Diabetes \& Vascular Medicine, Diabetes Research Centre, University of Leicester, UK.

\section{Anil Adisesh,}

Division Director, Occupational Medicine,

Department of Medicine, University of Toronto and St Michael's Hospital, Canada.

\section{Christopher Burton,}

Professor of Primary Medical Care, Academic Unit of Primary Medical Care, University of Sheffield, UK.

\section{Xin Hui S Chan,}

Clinical Research Fellow, Centre for Tropical Medicine and Global Health, University of Oxford, UK.

\section{Briana Coles}

Statistician/Epidemiologist, Diabetes Research Centre, University of Leicester, UK.

\section{Quentin Durand-Moreau,}

Assistant Professor, Division of Preventive Medicine, Department of Medicine, University of Alberta, Canada.

\section{Tanya Jackson,}

Research Associate, Division of Preventive Medicine, Department of Medicine, University of Alberta, Canada.

\section{Lawrence Ross,}

Professor Emeritus of Pediatrics, Division of Pediatric Infectious Diseases, Children's Hospital of Los Angeles; Keck School of Medicine, University of Southern California, US.

\section{Sebastian Straube}

Professor and Division Director, Division of Preventive Medicine, Department of Medicine, University of Alberta, Canada. 


\section{Elaine Toomey,}

Lecturer, School of Allied Health, University of Limerick, Ireland.

\section{Trisha Greenhalgh,}

Professor of Primary Care Health Sciences,

Nuffield Department of Primary Care Health

Sciences, University of Oxford, UK.

\section{Provenance}

Freely submitted; externally peer reviewed.

\section{REFERENCES}

1. Cook T, Kursumovic E, Lennane S. Exclusive: deaths of NHS staff from covid-19 analysed. HSJ 2020; 22 Apr: https://uww.hsj.co.uk/ exclusive-deaths-of-nhs-staff-from-covid-19analysed/7027471.article laccessed 6 Jul 2020).

2. Gehanno J, Bonneterre V, Andujar P, et al. [Evidences for a possible airborne transmission of SARS-CoV-2 in the COVID-19 crisis]. [Article in French]. Arch Mal Prof Enviro 2020; DOI: https://doi.org/10.1016/j.admp.2020.04.018.

3. World Health Organization. Modes of transmission of virus causing COVID19: implications for IPC precaution recommendations. 2020. https://wnw. who.int/news-room/commentaries/detail/ modes-of-transmission-of-virus-causingcovid-19-implications-for-ipc-precautionrecommendations (accessed 6 Jul 2020).

4. NHS England. Guidance and standard operating procedures. General practice in the context of coronavirus (COVID-19). Version 3.3.2020. https://www.england.nhs.uk/coronavirus/ wp-content/uploads/sites/52/2020/03/C0485 guidance-and-standard-operating-proceduresgeneral-practice-covid-19.pdf laccessed 6 Jul 2020).

5. Majeed A, Molokhia M, Pankhania B, Asanati $K$. Protecting the health of doctors during the COVID-19 pandemic. Br J Gen Pract 2020; DOl: https://doi.org/10.3399/bjgp20X709925.

6. Public Health England. COVID-19 personal protective equipment (PPE). 2020. https://umw gov.uk/government/publications/wuhan-novelcoronavirus-infection-prevention-and-control/ covid-19-personal-protective-equipment-ppe laccessed 6 Jul 2020).

7. World Health Organization. Infection prevention and control during health care when COV-19 is suspected. 2020. https:// wuw.who.int/publications/i/item/infectionprevention-and-control-during-health-carewhen-novel-coronavirus-(ncov)-infection-issuspected-20200125 (accessed 6 Jul 2020).

8. World Health Organization. Advice on the use of masks in the context of COVID-19. 2020 https://uww.who.int/publications/i/item/adviceon-the-use-of-masks-the-community-duringhome-care-and-in-health-care-settings-in-thecontext-of-the-novel-coronavirus-(2019-ncov)outbreak (accessed 6 Jul 2020).

9. Centers for Disease Control and Prevention, National Institute for Occupational Safety and Health. Hierarchy of controls. 2015. https:// www.cdc.gov/niosh/topics/hierarchy/default. html (accessed 6 Jul 2020).

10. Khunti K, Greenhalgh T, Chan XH, et al. What is

\section{Acknowledgements}

Kamlesh Khunti acknowledges support from the National Institute for Health Research Applied Research Collaboration - East Midlands (NIHR ARC - EM) and the Leicester Biomedical Research Centre.

DOI: https://doi.org/10.3399/bjgp20X710969

\section{ADDRESS FOR CORRESPONDENCE}

Kamlesh Khunti

Leicester Diabetes Centre, Leicester LE5 4PW, UK.

Email: kk22ale.ac.uk the evidence that COVID-19 personal protective equipment should include shoe covers? 2020 https://www.cebm.net/covid-19/what-is-theevidence-that-covid-19-personal-protectiveequipment-should-include-shoe-covers (accessed 6 Jul 2020).

11. Greenhalgh T, Chan XH, Khunti K, et al. What is the efficacy of standard face masks compared to respirator masks in preventing COVID-type respiratory illnesses in primary care staff? 2020 https://www.cebm.net/covid-19/what-is-theefficacy-of-standard-face-masks-comparedto-respirator-masks-in-preventing-covid-typerespiratory-illnesses-in-primary-care-staff accessed 6 Jul 2020).

12. Coles B, Burton C, Khunti K, et al. What is the effectiveness of protective gowns and aprons against COVID-19 in primary care settings? 2020. https://www.cebm.net/covid-19/what-isthe-effectiveness-of-protective-gowns-andaprons-against-covid-19-in-primary-caresettings (accessed 6 Jul 2020).

13. Khunti K, Greenhalgh T, Chan XH, et al. What is the efficacy of eye protection equipment compared to no eye protection equipment in preventing transmission of COVID-19-type respiratory illnesses in primary and community care? 2020. https://www.cebm.net/covid-19/ what-is-the-efficacy-of-eye-protectionequipment-compared-to-no-eye-protectionequipment-in-preventing-transmission-ofcovid-19-type-respiratory-illnesses-in-primaryand-community-care (accessed 6 Jul 2020).

14. US Food and Drug Administration. N95 respirators, surgical masks, and face masks. 2020. https://www.fda.gov/medical-devices/ personal-protective-equipment-infectioncontrol/n95-respirators-surgical-masks-andface-masks laccessed 6 Jul 2020).

15. Long Y, Hu T, Liu L, et al. Effectiveness of N95 respirators versus surgical masks against influenza: a systematic review and metaanalysis. J Evid Based Med 2020; DOI: https:// doi.org/10.1111/jebm.12381.

16. van Doremalen N, Bushmaker T, Morris DH et al. Aerosol and surface stability of SARS-CoV-2 as compared with SARS-CoV-1. N Engl J Med 2020; 382(16): 1564-1567.

17. Jefferson T, Del Mar C, Dooley L, et al. Physical interventions to interrupt or reduce the spread of respiratory viruses: systematic review. BMJ 2009; 339: b3675

18. Verbeek JH, Rajamaki B, ljaz S, et al. Personal protective equipment for preventing highly infectious diseases due to exposure to contaminated body fluids in healthcare staff. Cochrane Database Syst Rev 2020; 4(4):
CD011621

19. Guo YP, Li Y, Wong PL. Environment and body contamination: a comparison of two different removal methods in three types of personal protective clothing. Am J Infect Control 2014; 42(4): e39-e45.

20. Hall S, Poller B, Bailey C, et al. Use of ultraviolet-fluorescence-based simulation in evaluation of personal protective equipment worn for first assessment and care of a patient with suspected high-consequence infectious disease. J Hosp Infect 2018; 99(2): 218-228.

21. Government.UK. Technical specifications for personal protective equipment (PPE) - aprons specification 2. https://assets.publishing.service. gov.uk/government/uploads/system/uploads/ attachment_data/file/878203/BTB272_White_ Polymer_Aprons_Framework_Agreement_ Specification Lines Metric Dimensions Final_10022016_008_xlsx.pdf laccessed 6 Jul 2020).

22. French CE, McKenzie BC, Coope C, et al. Risk of nosocomial respiratory syncytial virus infection and effectiveness of control measures to prevent transmission events: a systematic review. Influenza Other Respir Viruses 2016; 10(4): $268-290$.

23. Gala CL, Hall C, Schnabel K, et al. The use of eye-nose goggles to control nosocomial respiratory syncytial virus infection. JAMA 1986; 256(19): 2706-2708

24. Ong SWX, Tan YK, Chia PY, et al. Air, surface environmental, and personal protective equipment contamination by severe acute respiratory syndrome coronavirus 2 (SARSCoV-2) from a symptomatic patient. JAMA 2020; 323(16): 1610-1612.

25. Ong SWX, Tan YK, Sutjipto S, et al. Absence of contamination of personal protective equipment (PPE) by severe acute respiratory syndrome coronavirus 2 (SARS-CoV-2). Infect Control Hosp Epidemiol 2020; 41(5): 614-616.

26. Pan American Health Organization. Requirements and technical specifications of personal protective equipment (PPE) for novel coronavirus (2019-ncov) in healthcare settings. 2020. https://iris.paho.org/bitstream/ handle/10665.2/51906/requirements-\%20PPEcoronavirus-eng. pdf? sequence $=1$ \&isAllowed $=y$ laccessed 6 Jul 2020).

27. Houghton C, Meskell P. Delaney H, et al Barriers and facilitators to healthcare workers' adherence with infection prevention and control (IPC) guidelines for respiratory infectious diseases: a rapid qualitative evidence synthesis. Cochrane Database Syst Rev 2020; 4(4): CD013582. 